\title{
Analisis Kekuatan Rangka pada Mesin Transverse Ducting Flange (TDF) Menggunakan Software Solid Works
}

\author{
Eko Prasetyo ${ }^{\left.1^{*}\right)}$, Rudi Hermawan ${ }^{2)}$, Muhammad Naufal Ibnu Ridho3), Istihara Ibnu Hajar ${ }^{3)}$ \\ Hasan Hariri ${ }^{1)}$, Erlanda Augupta Pane ${ }^{1)}$ \\ ${ }^{1}$ Jurusan Teknik Mesin, Universitas Pancasila \\ ${ }^{2} \mathrm{PT}$. Defa Angkasa Utama \\ ${ }^{3}$ Program Studi Diploma 3 Teknik Mesin, Universitas Pancasila \\ *eko170424@gmail.com \\ DOI: https://doi.org/10.21107/rekayasa.v13i3.8872
}

\begin{abstract}
In the industrial world, companies are required to be more effective and creative with the development of today's technology. Transverse ducting flange (TDF) machine is a machine that functions to make ducting flange products and form ducting connections, where there are several components in large quantities, so the design of the frame construction made must be strong to support these components. Responding to the cases that occurred, with the aims and objectives of this study, namely to determine the level of efficiency in the use of the design on a hollow galvanized steel frame measuring $(100 \times 50 \times 3,2) \mathrm{mm}$, by performing simulations using SolidWorks Premium 2019 software with static analysis features. using the finite element method. So with this research, we can find out whether the frame is receiving loads that exceed the yield strength limit or vice versa. The results of the research are three load-bearing areas received, with load values in a row, namely 11693,809 N, $266 \mathrm{~N}$, and 598,206 N. From the results of the three, it shows that the design of the frame construction that has been made is safe to use, because the calculation of the analysis meets the value requirements safety factor and the maximum stress simulation that occurs does not exceed the yield strength limit of the frame material.
\end{abstract}

Keywords: framework, solid-works, analysis, loading, transverse ducting flange

\section{PENDAHULUAN}

Dengan berkembangnya ilmu pengetahuan dan teknologi saat ini dunia perindustrian mengalami kemajuan yang begitu pesat. Kemajuan teknologi itu tak lepas dari dukungan khususnya dunia industri manufaktur, dimana terdapat industri dari yang berskala kecil maupun industri menengah dan sampai ke dalam skala besar (Wibowo, Raharjo \& Kusharjanta, 2014). Begitu juga dengan peningkatan kualitas sumber daya manusia dan teknologinya dengan penggunaan mesin-mesin canggih pada proses produksi yang bertujuan meningkatkan efisiensi dan efektifitas produksi. Pada industri skala menengah sering dijumpai teknologi penunjang produksi yang memerlukan mesin mulai dari yang berukuran sedang, maupun besar (Sunarto,

\section{Article History:}

Received: Oct, 22 ${ }^{\text {nd }}$ 2020; Accepted: Dec, $11^{\text {th }} 2020$

Rekayasa ISSN: $2502-5325$ has been Accredited by Ristekdikti (Arjuna) Decree: No. 23/E/KPT/2019 August 8th, 2019 effective until 2023
Sisworo \& Prasojo, 2018). Seperti halnya pada PT. Defa Angkasa Utama yaitu perusahaan yang bergerak dalam memproduksi serta memasarkan produk saluran angin (ducting) yang dibutuhkan pada industri HVAC (Heating Ventilation Air Conditioning). Ducting sendiri diartikan sebagai pendistribusi udara untuk mengalirkan udara antara sistem udara, serta dari penghasil udara ke tiap-tiap ruangan dengan peralatan terminal dan ducting flange berfungsi sebagai penghubung sambungan antara dua unit ducting menjadi satu kesatuan yang utuh (Ramadhanis, 2019). HVAC memiliki peran penting dalam industri terutama untuk gedung-gedung seperti perkantoran, mall, apartemen, serta Industri-industri besar yang memerlukan sistem ventilasi yang baik dan

\section{Cite this as:}

Prasetyo, E., Hermawan, R., Ridho, M.N.I., Hajar, I.I., Hariri, H \& Pane, E.A (2020). Analisis Kekuatan Rangka pada Mesin Transverse Ducting Flange (TDF) Menggunakan Software Solid Works. Rekayasa, 13 (3), 299-306. doi: https://doi.org/10.21107/rekayasa.v13i3.8872

(c) 2020 Eko Prasetyo, Rudi Hermawan, Muhammad Naufal Ibnu Ridho, Istihara Ibnu Hajar, Hasan Hariri, Erlanda Augupta Pane 
tentunya bertujuan untuk menjaga kelembaban udara. Dengan begitu untuk merealisasikan proses produksi pada perusahaan ini maka diperlukan suatu mesin penunjang agar kegiatan produksi berjalan dengan baik (Husodo \& Siagian, 2014).

Mesin Transverse Ducting Flange atau yang biasa dikenal dengan sebutan mesin TDF, merupakan salah satu mesin yang digunakan untuk memproduksi ducting, yang dimana berfungsi sebagai membentuk (forming) yang menggunakan komponen roller sebagai media pembentukan benda kerja dengan cara merol forming benda kerja tersebut. Roll forming juga disebut contour roll forming adalah proses pembengkokan kontinu dimana menghasilkan bentuk sesuai dengan pembentukan dari roller tersebut (Groover, 2010).

Salah satu komponen utama yang terdapat pada mesin TDF yaitu rangka. Rangka merupakan bagian mendasar yang paling penting khususnya penggunaan pada permesinan, karena fungsi rangka yaitu sebagai pendukung komponenkomponen pada mesin itu sendiri, dan serta mampu menahan gaya aksial, normal dan momen untuk menjaga kestabilan pada mesin. Kekuatan rangka tergantung pada bentuk atau jenis kontruksinya yang dimana untuk menahan pembebanan torsi dari mesin dan juga menahan kejutan yang diberikan saat mesin bergerak (Adriana \& Masrianor, 2017).

Mesin TDF yang terdapat di PT. Defa Angkasa Utama menggunakan konstruksi rangka dari besi hollow dengan jenis material galvanis, karena besi hollow galvanis merupakan salah satu bahan yang sering digunakan pada kontruksi khususnya permesinan industri dan memiliki karakteristik bahan material yang kuat serta kokoh dalam menopang beban yang berlebih (Fitriana 2019). Melihat fungsi dari komponen perkomponen suatu mesin dan beragam beban yang diterima oleh suatu rangka, maka diperlukan untuk menganalisis desain, agar mengetahui tingkat keamanan dari pada penggunaan desain konstruksi rangka tersebut. Maka dari itu untuk lebih mengetahui tingkat keamanan pada struktur rangka mesin TDF diperlukan software penunjang untuk menganalisis kasus tersebut.

Berdasarkan pembahasan diatas, penelitian ini dilakukan untuk menganalisis kekuatan rangka pada mesin TDF, yang dimana bertujuan untuk mengetahui nilai tegangan (stress) dan nilai safety factor pada rangka, apakah nilai analisis rangka mesin TDF ini melebihi batas yield strength dan aman untuk digunakan ataupun sebaliknya. Sekecil apapun gaya yang bekerja, maka benda akan mengalami perubahan bentuk dan ukuran.

Perubahan ukuran secara fisik ini disebut sebagai deformasi. Deformasi ada dua macam, yaitu deformasi elastis dan plastis. Deformasi elastis adalah perubahan bentuk benda yang bisa kembali kebentuk seperti semula, sedangkan deformasi plastis adalah kebalikannya, yang dimana benda mengalami perubahan bentuk secara tetap (Abidin and Rama 2015). Dalam sebuah rancangan desain untuk menganalisis kekuatan rangka, kriteria yang biasa digunakan adalah kekuatan luluh (yield strength), yaitu nilai tegangan terendah dimana material mengalami deformasi plastis. Kekuatan material merupakan kemampuan material untuk menahan beban maksimum sebelum patah. Dalam artiannya nilai tegangan material yang masih dibawah yield strength, secara deformasi material akan dapat kembali kebentuk semula dan material aman untuk digunakan (Wibawa 2019).

Metode Elemen Hingga (MEH) telah membuktikan kehandalannya dalam memecahkan persoalan-persoalan dibidang mekanika kontinu. Dengan menganalisis tegangan serta regangan dengan menggunakan fitur statik, analisis tegangan terhadap suatu desain itu sendiri dapat dengan mudah diperhitungkan dengan menggunakan software analisis, salah satunya yaitu software SolidWorks (Nugroho 2015). Oleh karena itu penelitian memilih simulasi dengan menggunakan software yang berbasis metode elemen hingga (finite element analysis program) yaitu dengan software SolidWorks (Abidin \& Rama, 2015).

SolidWorks yaitu program rancang bangun yang banyak digunakan untuk mengerjakan desain produk, desain mesin, desain mould, desain konstruksi, dan untuk keperluan lain-lain terkhusus dalam bidang teknik sesuai dengan penelitian yang dilakukan. SolidWorks dilengkapi dengan tools yang digunakan untuk menghitung dan analisis hasil desain seperti tegangan, regangan, maupun pengaruh suhu, angin, dan lain-lain. SolidWorks sendiri juga merupakan pemodelan yang berbasis fitur parametrik, yang dimana semua objek dan hubungan antar geometrik dapat dimodifikasi kembali meskipun 
geometriknya sudah jadi tanpa perlu mengulang kembali dari awal (Akin 2010).

\section{METODE PENELITIAN}

\section{Pengumpulan data}

Data yang didapat berupa rancangan desain 3D rangka mesin TDF yang telah dibuat dengan menggunakan software SolidWorks Premium 2019. Material yang digunakan pada rangka ini yaitu besi hollow galvanis berukuran $(100 \times 50 \times$ $3,2) \mathrm{mm}$ dan dengan nilai yield strength sebesar $550 \mathrm{MPa}$ atau $5,5 \mathrm{e}+8 \mathrm{~N} / \mathrm{m}^{2}$.

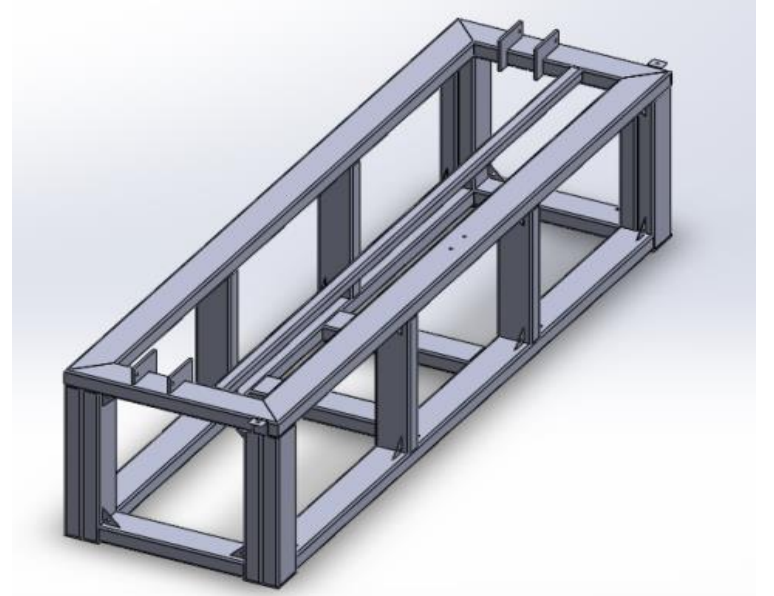

Gambar 1. Desain Rangka Mesin TDF
Data juga berupa asumsi dari beban komponen-komponen mesin yang berkaitan dengan rangka mesin tersebut, yang dimana diperoleh dari software SolidWorks Premium 2019 dengan menggunakan fitur mass properties, sehingga dapat diketahui beban komponen dan sesuai dengan material nya. Massa pada masingmasing komponen mesin TDF yang dapat dilihat pada Tabel 1.

\section{Analisis Hasil Rancangan}

Analisis simulasi dilakukan dengan menggunakan fitur statis oleh software SolidWorks Premium 2019. Simulasi dengan software ini berguna menjalankan analisis untuk membuktikan validitas dari sebuah desain (Wibawa 2019). Hasil data dari fitur statis ini yaitu dapat diketahui parameter nilai sebagai berikut:

a. Strain (regangan)

Regangan dapat dikatakan tingkat deformasi yang dapat memanjang, memendek, membesar, mengecil, dan sebagainya.

b. Displacement (perpindahan)

Yaitu perpindahan material dari titik awal ke titik akhir yang sudah terkena gaya tekan atau beban (force) dari proses pengepresan (Munir, Qomaruddin, and Winarso 2019).

Tabel 1. Massa Komponen Mesin TDF

\begin{tabular}{|c|c|c|c|}
\hline No. & Nama Komponen & Deskripsi & Massa (grams) \\
\hline 1 & 15 Roller LA dan 16 Roller LB & Stainless Steel & 103655,91 \\
\hline 2 & 16 Roller RA dan 15 Roller RB & Stainless Steel & 65354,09 \\
\hline 3 & Gear type $1 \times 12$ & $\mathrm{~S} 45 \mathrm{C}$ & $469,80 \times 12=5637,6$ \\
\hline 4 & Gear type $2 \times 2$ & S45C & $126,82 \times 2=253,64$ \\
\hline 5 & Gear type $3 \times 22$ & S45C & $272,37 \times 22=5992,14$ \\
\hline 6 & Gear type $4 \times 15$ & S45C & $267,37 \times 15=4010,55$ \\
\hline 7 & Shaft type $1 \times 12$ & S45C & $1186,66 \times 12=14239,92$ \\
\hline 8 & Shaft type $2 \times 12$ & S45C & $278,37 \times 12=3340,44$ \\
\hline 9 & Shaft type $3 \times 15$ & S45C & $12528,88 \times 15=187933,2$ \\
\hline 10 & Shaft type $4 \times 2$ & S45C & $190,75 \times 2=381,5$ \\
\hline 11 & Shaft type $5 \times 24$ & S45C & $332,14 \times 24=7971,36$ \\
\hline 12 & Mounting upper side type $1 \times 2$ & Alloy Steel & $32114,26 \times 2=595974,07$ \\
\hline 13 & Mounting upper type $2 \times 2$ & Alloy Steel & $17633,35 \times 2=32114,26$ \\
\hline 14 & Mounting lower side × 2 & Alloy Steel & $71185,08 \times 2=142370,16$ \\
\hline 15 & Bearing 6007 RS × 76 & Stainless Steel & $165,77 \times 76=12598,52$ \\
\hline 16 & Bearing 60072 RS $\times 64$ & Stainless Steel & $165,77 \times 64=10609,28$ \\
\hline 17 & Stem & Plain Carbon Steel & 1179,04 \\
\hline 18 & Cantilever $1 \times 2$ & Galvanized Steel & $574,9 \times 2=1149,8$ \\
\hline 19 & Cantilever 2 & Galvanized Steel & 553,54 \\
\hline 20 & Motor listrik & BLA-100L 2-4, 4 HP & 23000 \\
\hline 21 & Gearbox & NMRV 110, Ratio 1:30 & 35000 \\
\hline 22 & Alas transmisi & Plain Carbon Steel & 3000 \\
\hline
\end{tabular}


c. Stress (tegangan)

Tegangan itu sendiri merupakan gaya reaksi atau gaya yang bekerja untuk mengembalikan suatu benda, kepada bentuk semula persatuan luas yang terbagi rata pada permukaannya.

Selain itu, tujuan dari fitur ini yaitu untuk mengetahui tegangan yang dilakukan oleh software SolidWorks menggunakan metode analisis elemen hingga. Analisis elemen hingga merupakan teknik numerik matematis untuk menghitung kekuatan dan perilaku struktur komponen teknik dengan membagi obyek menjadi bentuk jala (mesh). Analisis statis menggunakan metode elemen hingga yaitu teknik yang menentukan tegangan pada material dan struktur yang mengalami beban atau gaya statis maupun dinamis, sehingga mengetahui karakteristik kekuatan rangka dalam menerima beban kerja dari komponen-komponen yang terdapat pada mesin TDF (Wibawa et al. 2018). Safety factor digunakan dalam banyak analisis sebagai parameter keberhasilan atau kegagalan suatu analisis tersebut dan agar terjamin keamanannya. Dengan rumus safety factor yang dapat digunakan yaitu sebagai berikut:

$$
S f=\frac{\sigma \text { yield strength }}{\sigma \max \text { von mises }}
$$

Keterangan :

$S f=$ Safety Factor

$\sigma$ yield strength = kekuatan luluh material

$\sigma$ max von mises $=$ tegangan kerja maksimal

\section{HASIL DAN PEMBAHASAN \\ Diagram Benda Bebas}

Hasil analisis pembebanan dengan diagram benda bebas pada rangka adalah sebagai berikut.

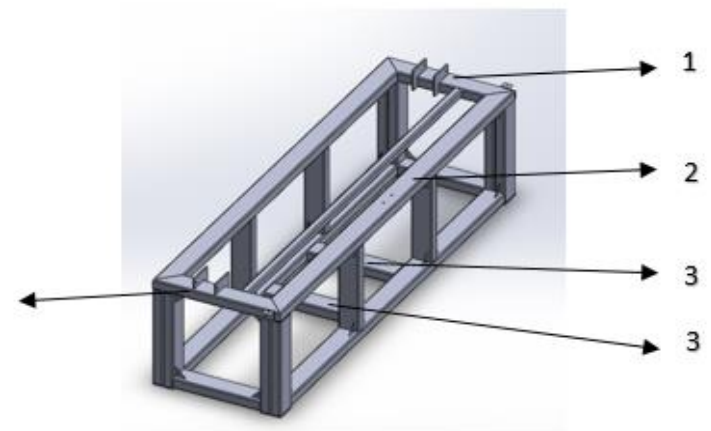

Gambar 2. Bagian Rangka yang Dikenakan Beban

\section{a. Fixture}

Fixture (pencekaman) merupakan langkah awal dari proses analisis ini, yang berartikan suatu desain yang dikembangkan dengan menggunakan simbolisasi rancangan fixture untuk mempermudah penetapan pada setiap fungsi bagian dari fixture atau kata lain yaitu bagian yang dibuat tidak bergerak, dan biasanya dipilih pada bagian kaki rangka (Komara, 2020). Berikut proses fixture yang ditempatkan pada ke empat kaki rangka seperti yang ditunjukkan pada Gambar 3.

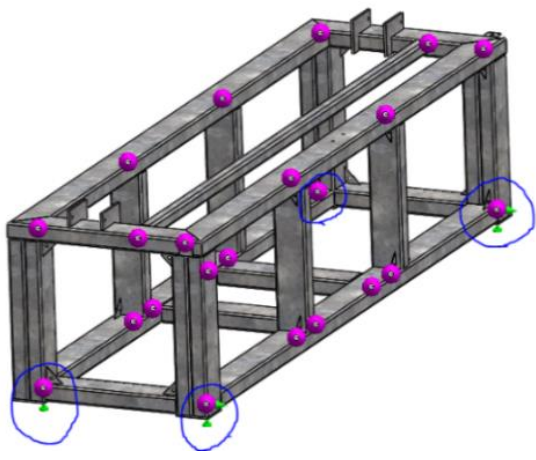

Gambar 3. Fixture pada Rangka

\section{b. Pembebanan Rangka Area 1}

Pembebanan dilakukan pada area rangka bagian atas dengan dua sisi. Seperti yang terlihat pada Tabel 1 dengan nomor urut 1 sampai 16, area bagian ini menumpu komponen mounting, shaft, gear, roller, serta bearing, maka beban yang dikenakan pada bagian ini yaitu sebesar 1192436,64 grams atau 11693,809 N (Gambar 4).

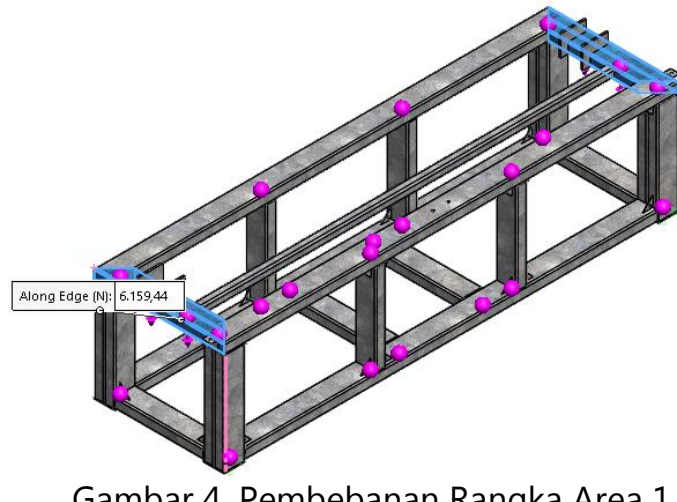

\section{c. Pembebanan Rangka Area 2}

Pembebanan dilakukan pada area rangka bagian atas dengan satu sisi. Seperti yang ditunjukkan pada Tabel 1 dengan nomor urut 17 sampai 19, area bagian ini menumpu komponen stem, cantilever 1 dan cantilever 2, maka beban yang dikenakan pada bagian ini yaitu sebesar 2882.38 grams atau 28,266 N (Gambar 5). 


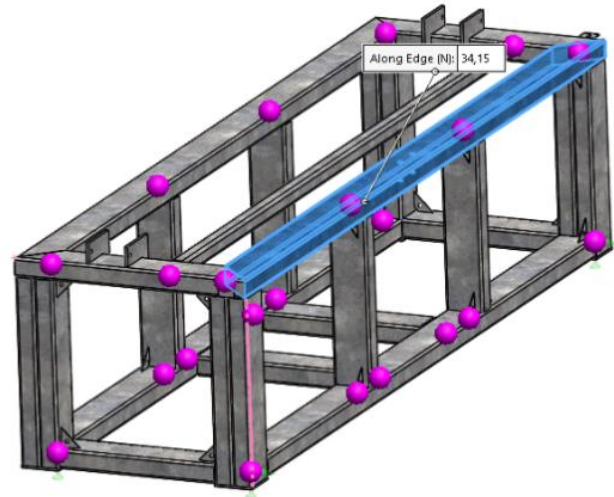

Gambar 5. Pembebanan Rangka Area 2

\section{d. Pembebanan Rangka Area 3}

Pembebanan dilakukan pada area rangka bagian bawah dengan dua sisi. Seperti yang ditunjukkan pada Tabel 1 dengan nomor urut 20 sampai 22, area bagian ini menumpu komponen motor listrik, gearbox, dan alas transmisi, maka beban yang dikenakan pada bagian ini yaitu sebesar 61000 grams atau 598,206 N (Gambar 6).

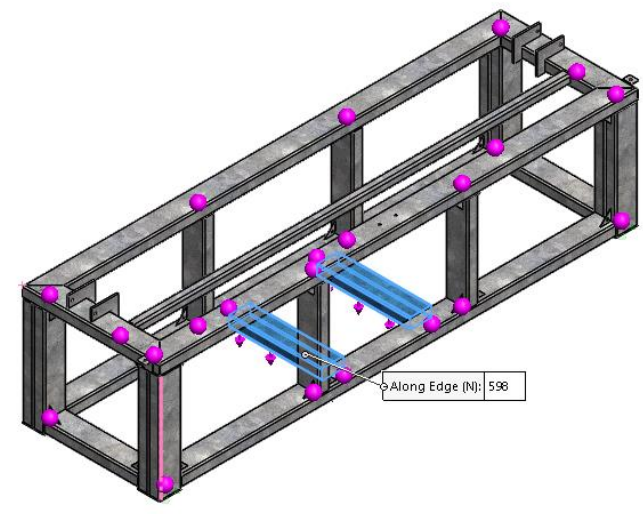

Gambar 6. Pembebanan Rangka Area 3

\section{Hasil Analisis}

\section{a. Pembebanan Rangka Area 1}

Nilai analisis simulasi yang diketahui pertama yaitu strain, bahwa besaran beban awal yang diberikan pada rangka di area 1 ini sebesar $11693,809 \mathrm{~N}$ dan besarnya regangan maksimal yang terjadi adalah sebesar 3,183e-04 N/m² dengan ditunjukan oleh diagram warna pada area yang berwarna merah (Gambar 7). Adapun pada analisis simulasi displacement yang telah dilakukan, nilai displacement terbesar pada pembebanan rangka area 1 ditunjukan oleh diagram warna yang berwarna merah dengan nilai sebesar 7,218e-02 mm (Gambar 8).

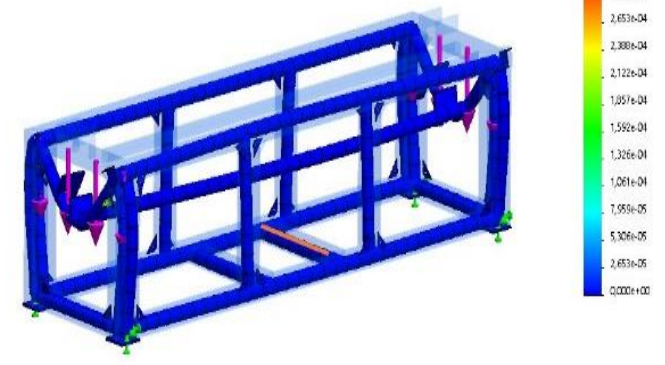

Gambar 7. Hasil Analisis Strain pada Pembebanan Rangka Area 1

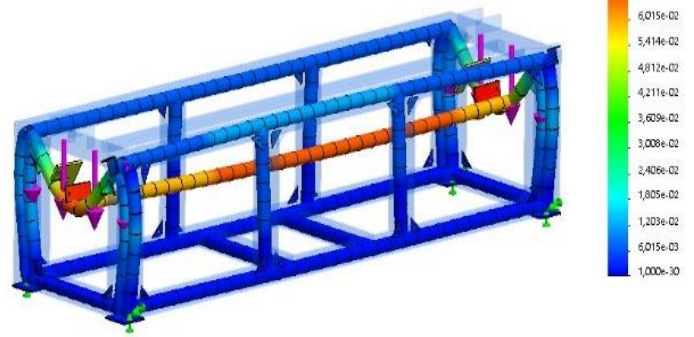

Gambar 8. Hasil Analisis Displacement pada Pembebanan Rangka Area 1

Menurut hasil dari diagram warna hasil simulasi yang terlihat pada Gambar 10. dapat diketahui bahwa nilai stress atau nilai tegangan maksimal yang didapatkan yaitu sebesar $4,533 \times$ $10^{4} \mathrm{~N} / \mathrm{m}^{2}$, yang dimana menunjukkan bahwa nilai tegangan maksimum yang terjadi masih berada di bawah nilai yield strength material rangka mesin TDF (Gambar 9).

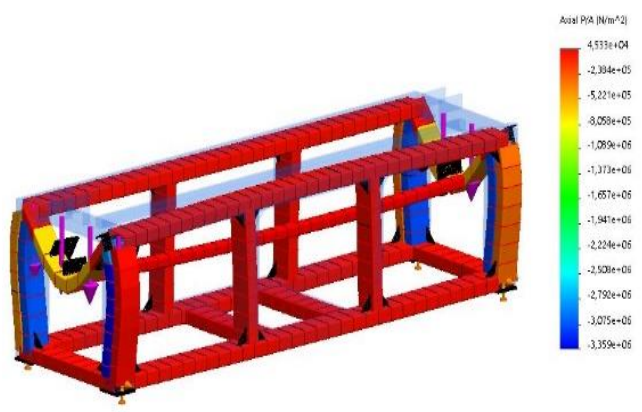

\section{Gambar 9. Hasil Stress pada Pembebanan Rangka Area 1}

Untuk mengetahui bahwa pembebanan rangka pada area 1 aman digunakan, maka dapat dihitung nilai safety factor dengan persamaan (1), yaitu: 


$$
\begin{aligned}
S f & =\frac{5,5 \times 10^{8} \mathrm{~N} / \mathrm{m}^{2}}{4,533 \times 10^{4} \mathrm{~N} / \mathrm{m}^{2}} \\
& =12133,245
\end{aligned}
$$

Berdasarkan hasil nilai safety factor pembebanan rangka pada area 1 ini telah melebihi dari nilai yang dipersyaratkan, sehingga rancangan rangka yang telah dibuat untuk pembebanan pada area 1 ini, sangat aman untuk menahan beban sebesar 11693,809 N.

\section{b. Pembebanan Rangka Area 2}

Nilai analisis simulasi yang diketahui pertama yaitu strain, bahwa besaran beban awal yang diberikan pada rangka di area 2 ini sebesar $28,266 \mathrm{~N}$ dan besarnya regangan maksimal yang terjadi adalah sebesar 1,897e-06 N/m² dengan ditunjukan oleh diagram warna pada area yang berwarna merah (Gambar 10).
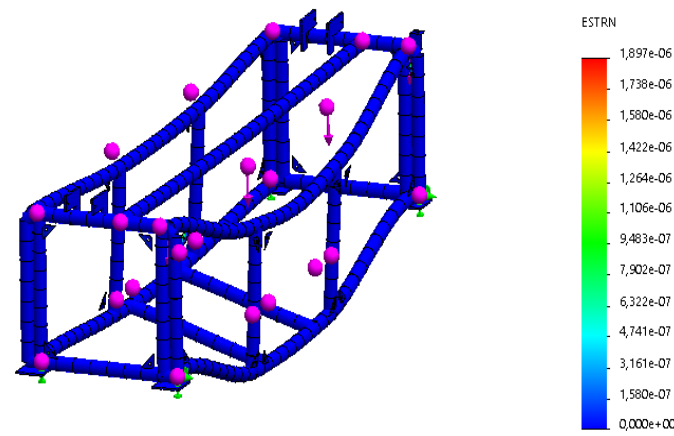

Gambar 10. Hasil Analisis Strain pada Pembebanan Rangka Area 2

Adapun pada analisis displacement yang telah dilakukan, nilai displacement terbesar pada pembebanan rangka area 2 ditunjukan oleh diagram warna yang berwarna merah dengan nilai sebesar 2,575e-03 mm (Gambar 11).
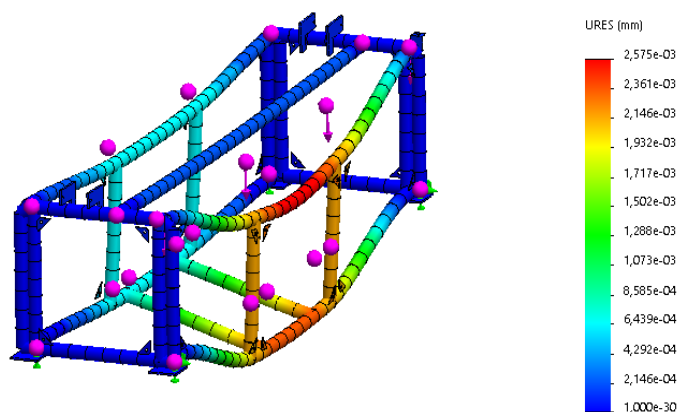

Gambar 11. Hasil Analisis Displacement pada Pembebanan Rangka Area 2
Berdasarkan diagram warna hasil simulasi yang terlihat pada Gambar 13. dapat diketahui bahwa nilai stress atau nilai tegangan maksimal yang didapatkan yaitu sebesar $3,016 \times 10^{3} \mathrm{~N} / \mathrm{m}^{2}$, yang dimana menunjukkan bahwa nilai tegangan maksimum yang terjadi masih berada di bawah nilai yield strength material rangka mesin TDF (Gambar 12).
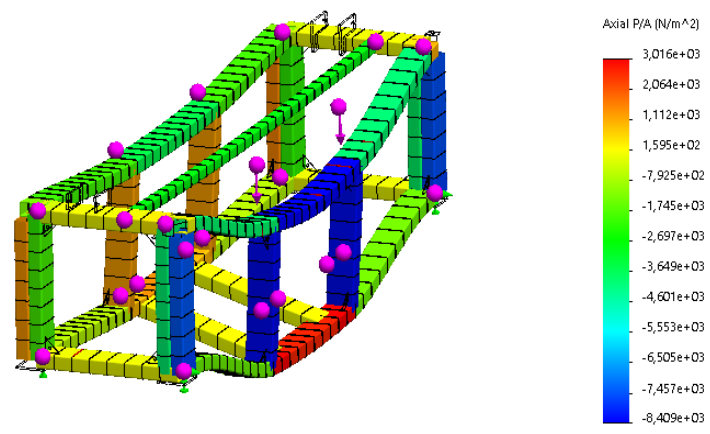

\section{Gambar 12. Hasil Stress pada Pembebanan Rangka Area 2}

Untuk mengetahui bahwa pembebanan rangka pada area 2 aman digunakan, maka dapat dihitung nilai safety factor dengan persamaan (1), yaitu:

$$
\begin{aligned}
S f & =\frac{5,5 \times 10^{8} \mathrm{~N} / \mathrm{m}^{2}}{3,016 \times 10^{3} \mathrm{~N} / \mathrm{m}^{2}} \\
& =182360,743
\end{aligned}
$$

Hasil nilai safety factor pembebanan rangka pada area 2 ini telah melebihi dari nilai yang dipersyaratkan, sehingga rancangan rangka yang telah dibuat untuk pembebanan pada area 2 ini, sangat aman untuk menahan beban sebesar $28,266 \mathrm{~N}$.

\section{c. Pembebanan Rangka Area 3}

Nilai analisis simulasi yang diketahui pertama yaitu strain, bahwa besaran beban awal yang diberikan pada rangka di area 3 ini sebesar $598,206 \mathrm{~N}$ dan besarnya regangan maksimal yang terjadi adalah sebesar 4,822e-05 N/m² dengan ditunjukan oleh diagram warna pada area yang berwarna merah (Gambar 13). Adapun pada analisis displacement yang telah dilakukan, nilai displacement terbesar pada pembebanan rangka area 3 ditunjukan oleh diagram warna yang berwarna merah dengan nilai sebesar 1,032e-01 mm (Gambar 14). 


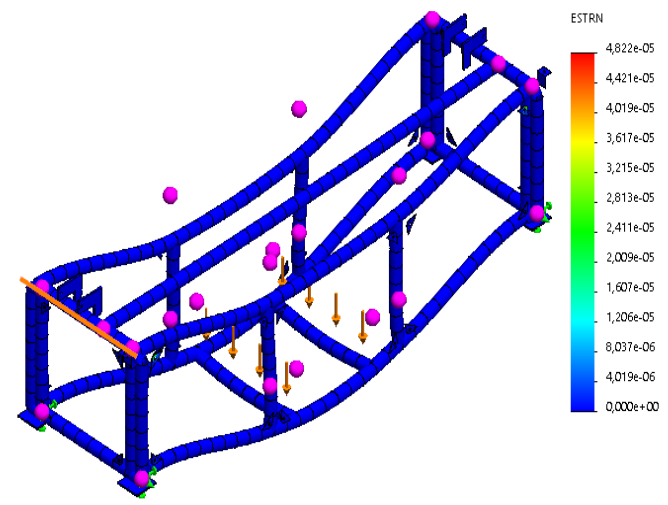

Gambar 13. Hasil Analisis Strain pada Pembebanan Rangka Area 3

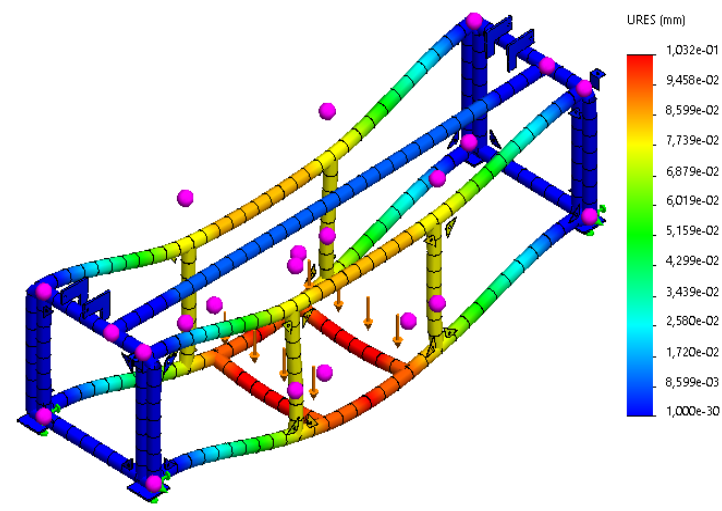

Gambar 14. Hasil Analisis Displacement pada Pembebanan Rangka Area 3

Berdasarkan diagram warna hasil simulasi yang terlihat pada Gambar 13. dapat diketahui bahwa nilai stress atau nilai tegangan maksimal yang didapatkan yaitu sebesar $1,635 \times 10^{5} \mathrm{~N} / \mathrm{m}^{2}$, yang dimana menunjukkan bahwa nilai tegangan maksimum yang terjadi masih berada di bawah nilai yield strength material rangka mesin TDF.

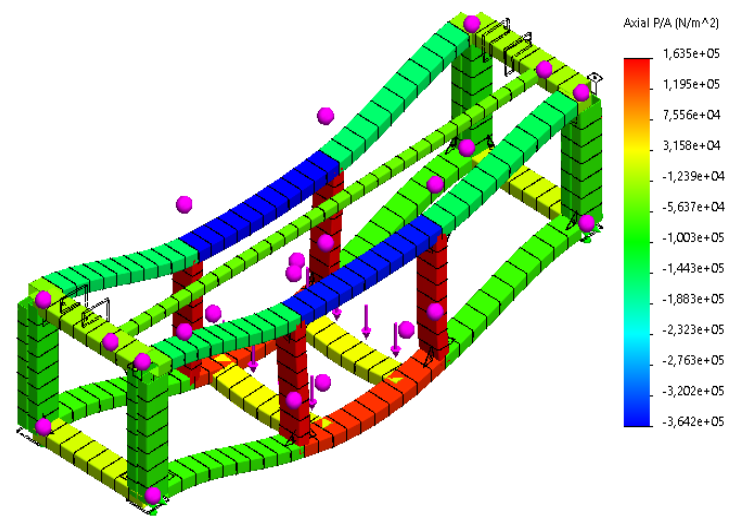

Gambar 15. Hasil Stress pada Pembebanan Rangka Area 3
Untuk mengetahui bahwa pembebanan rangka pada area 3 aman digunakan, maka dapat dihitung nilai safety factor dengan persamaan (1), yaitu:

$$
\begin{aligned}
S f & =\frac{5,5 \times 10^{8} \mathrm{~N} / \mathrm{m}^{2}}{1,635 \times 10^{5} \mathrm{~N} / \mathrm{m}^{2}} \\
& =3363,914
\end{aligned}
$$

Hasil nilai safety factor pembebanan rangka pada area 3 ini telah melebihi dari nilai yang dipersyaratkan, sehingga rancangan rangka yang telah dibuat untuk pembebanan pada area 3 ini, sangat aman untuk menahan beban sebesar $598,206 \mathrm{~N}$.

\section{KESIMPULAN DAN SARAN Kesimpulan}

Kesimpulan yang didapat dari penelitian ini diantaranya sebagai berikut:

1. Analisis rangka mesin TDF yaitu melakukan pembebanan benda bebas pada rangka di area 1,2 , dan 3 dengan variasi nilai pembebanannya berturut-turut yaitu sebesar $11693,809 \mathrm{~N}, 28,266 \mathrm{~N}$, dan 598,206 $\mathrm{N}$.

2. Desain rangka mesin TDF yang telah dibuat sangat aman untuk menopang beban, hal ini karena nilai safety factor pembebanan rangka pada ke-3 area ini telah memenuhi nilai yang dipersyaratkan, dengan ke-3 nilai safety factor berturut-turut yaitu 12133,245 , 182360,743, dan 3363,914.

3. Hasil tegangan maksimum yang terjadi dari ke-3 simulasi tersebut masih berada di bawah nilai yield strength material rangka mesin TDF yang bernilai $5,5 \times 10^{8} \mathrm{~N} / \mathrm{m}^{2}$. Dan hasil ke-3 nilai tegangan maksimum berturut-turut yaitu $4,533 \times 10^{4} \mathrm{~N} / \mathrm{m}^{2}$, $3,016 \times 10^{3} \mathrm{~N} / \mathrm{m}^{2}$, dan $1,635 \times 10^{5} \mathrm{~N} / \mathrm{m}^{2}$.

4. Semakin besar nilai yield strength terhadap suatu material, maka semakin aman struktur material tersebut untuk digunakan.

\section{Saran}

Penelitian selanjutnya diharapkan untuk lebih memperhatikan terhadap merancang konstruksi rangka suatu mesin, dengan cara mengklarifikasikan komponen perkomponen dengan permukaan elemen penopangnya, sehingga mengurangi tingkat kekhawatiran 
terhadap kerusakan pada rangka maupun mesin itu sendiri.

\section{DAFTAR PUSTAKA}

Abidin, Z., \& Rama, B. (2015). Analisa distribusi tegangan dan defleksi connecting rod sepeda motor 100 cc menggunakan metode elemen hingga. Jurnal Rekayasa Mesin Universitas Sriwijaya, 15(1), 30-39.

Adriana, M., B.P, A. A., \& Masrianor, M. (2017). Rancang bangun rangka (chasis) mobil listrik roda tiga kapasitas satu orang. Jurnal Elemen, 2(4), 129-133. https://doi.org/10.34128/je.v4i2.64.

Akin, J. E. 2010. Finite element analysis concepts: via solidworks, 2010 ed. World Scientific.

Fitriana, N. (2019). Implementasi desain 'name board' desa wisata jambu gondangmanis kabupaten jombang. Jurnal Pengabdian Masyarakat Progresif Humanis Brainstorming, 2(1), 44-52. https://doi.org/10.30591/japhb.v2i1.1288.

Groover, M. 2010. Fundementals of modern manufacturing materials, processes and systems. John Wiley \& Sons 493.

Husodo, B. Y., \& Siagian, N. A. (2014). Analisa audit konsumsi energi sistem hvac (heating, ventilasi, air conditioning) di terminal $1 a$, 1b, dan 1c bandara soekarno-hatta. Jurnal Teknologi Elektro, 5(1), 49-58. https://doi.org/10.22441/jte.v5i1.761.

Komara, A. I. (2020). Perancangan ulang machining fixture untuk produk cylinder head dan cover crankcase tipe 168. Machine: Jurnal Teknik Mesin, 6(1), 1-7. https://doi.org/10.33019/jm.v6i1.1367.

Munir, M. M., Qomaruddin, Q., \& Winarso, R. (2019). Perancangan dan simulasi punch mesin pres batako. Jurnal Crankshaft, 3(2),
1-6.

https://doi.org/10.24176/crankshaft.v2i1.3 $\underline{096}$.

Nugroho, C. B. (2015). Analisa kekuatan rangka pada traktor ( force analysis frame on tractor ). Jurnal Integrasi, 7(2), 104-107.

Ramadhanis, M. (2019). Perencanaan ducting pada gedung serbaguna. Jurnal PETRA, $6(1), 1-9$.

Sunarto, S., Sisworo, S., \& Prasojo, A. Z. (2018). Rancang bangun mesin roll bending pipa evaporator freezer kapal dengan motor listrik 1 hp. Jurnal Rekayasa Mesin, 105-108. https://doi.org/10.32497/rm.v13i3.1280.

Wibawa, L. A. N., Desain, , Kekuatan, A., Tempat, R., Di Balai, S., Garut, L., Metode, M., Hingga, E., Ari, L., Wibawa, N., Teknologi, B. U., Antariksa, P., Atmosfer, D., Penerbangan, L., \& Nasional, A. (2018). Desain dan analisis kekuatan rangka tempat sampah di balai lapan garut menggunakan metode elemen hingga. Jurnal Teknik Mesin, 1(2), 64-68.

Wibawa, L. A. N. (2019). Desain dan analisis kekuatan rangka lemari perkakas di balai lapan garut menggunakan metode elemen hingga. Machine: Jurnal Teknik Mesin, 2(5), 45-50. https://doi.org/10.33019/jm.v5i2.787.

Wibawa, L. A. N. (2019). Desain dan analisis kekuatan rangka meja kerja (workbench) balai lapan garut menggunakan metode elemen hingga. Jurnal Teknik Mesin ITI, 3(1), 13-17. https://doi.org/10.31543/jtm.v3i1.216.

Wibowo, T. A., Raharjo, W. P., \& Kusharjanta, B. (2014). Perancangan dan analisis kekuatan konstruksi mesin tekuk plat hidrolik. Mekanika, 12(2), 63-70. 